\title{
Bo Sun and the Development of Neonatology in China
}

\author{
Christian P. Speer ${ }^{a}$ Henry L. Halliday ${ }^{b}$ \\ a University Children's Hospital, University of Würzburg, Würzburg, Germany; ${ }^{b}$ Retired Professor of Child Health, \\ Queen's University of Belfast, Belfast, UK
}

Bo Sun was born in Shanghai in 1955. His parents were physicians, and he grew up with 2 brothers and 1 sister. $\mathrm{He}$ experienced the chaotic era of the "Great Cultural Revolution" in his teenage years through to early adulthood. After leaving middle school in 1972, Bo Sun was employed for nearly six years as a mechanical worker before being admitted to medical school in Shanghai in 1978, when the university system was reinstated in China. In 1983, he graduated from the Shanghai Second Medical University with a medical degree (MD) and continued his residency and postgraduate training in clinical pathology and research at the Children's Hospital of Shanghai Medical University. During this period, he obtained knowledge and skills in pediatric, clinical, and experimental pathology as well as in neonatal lung histopathology.

In 1987, Bo Sun was awarded a visiting fellowship from the Swedish Heart-Lung Foundation and Karolinska Institute, Stockholm, and he spent six years working with Bengt Robertson, a pioneer in surfactant research [1]. During this time, he developed experimental methods to characterize lung pathobiology, respiratory physiology, and the pharmacology of surfactant in immature animal lungs, and was involved in several important research projects which enabled him to understand surfactant function in models of acute lung injury [2]. Bo Sun also spent a year in 1991 as a visiting research fellow at the Perinatal Research Center of UCLA-Harbor Medical

\section{KARGER}

(C) 2017 S. Karger AG, Basel

E-Mail karger@karger.com

www.karger.com/neo
Bo Sun

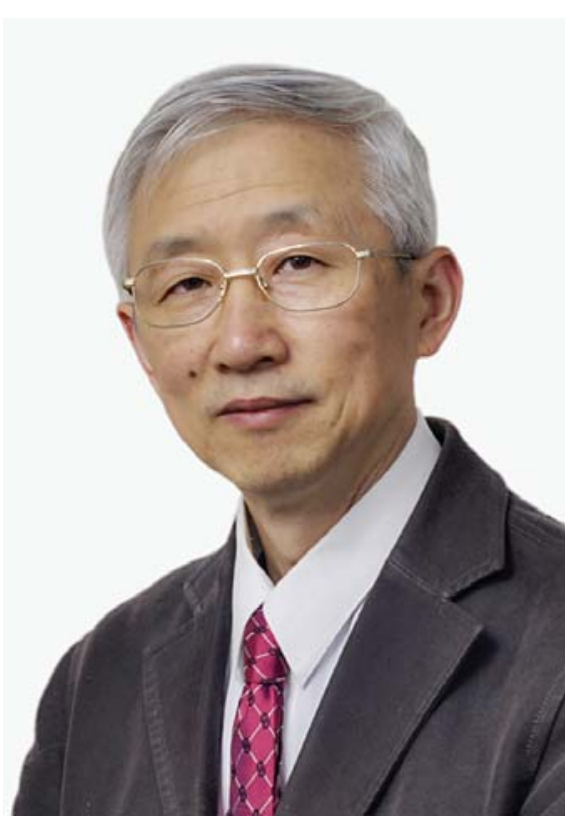

Center, Los Angeles, CA, USA. With Prof. Alan Jobe, he studied the pharmacodynamics and pharmacokinetics of surfactant, and the role of phospholipids and surfactant protein $A$ in interactions with various proteins which had been identified as potential inhibitors of surfactant function [3]. He subsequently focused on surfactant inactiva-

Prof. Christian P. Speer, MD, FRCPE

University Children's Hospital, University of Würzburg

Josef-Schneider-Strasse 2

DE-97080 Würzburg (Germany)

E-Mail speer_c@ukw.de 
tion by meconium and the potential benefit of surfactant therapy in experimental models of meconium aspiration syndrome (MAS) [4-6]. Some of these studies were included in his thesis for a doctorate in medical science $(\mathrm{PhD})$ at the Karolinska Institute.

In 1994, Bo Sun returned to the Children's Hospital of Shanghai Medical University and established his own research laboratory. He received a grant from the China Medical Board of New York, a foundation supporting clinical education and research in China and other Asian countries. With this grant, he focused on the respiratory problems of neonates and children requiring mechanical ventilation in China. At this time, these technologies were mainly confined to the major cities of coastal provinces, but were lacking in most areas of the country. Realizing this great demand, Bo Sun established a series of continuous education programs aimed at spreading knowledge of neonatal and pediatric intensive care as well as advanced technologies in the management of both neonatal respiratory distress syndrome (RDS) and infants and children with hypoxemic respiratory failure all over China.

In 1999, Bo Sun was appointed Professor in Pediatrics by the Ministry of Education, and since 2005, he has held a Chair in Pediatrics endowed by the Fudan University, Shanghai. He established a collaborative study group in neonatal respiratory diseases together with directors of neonatal intensive care units (NICUs) in different regions of China, and has conducted multicenter studies implementing advanced technologies into respiratory therapy for preterm and term neonates. Technologies, such as natural surfactant and continuous positive airway pressure, were introduced in the late 1990s and early 2000s, and are now widely used in all provinces as routine respiratory support strategies. Bo Sun also introduced inhaled nitrogen oxide (iNO) for the treatment of persistent pulmonary hypertension of the newborn, and this therapy is still subject to investigational use. He has also been involved with pediatric intensivists in establishing extracorporeal membrane oxygenation for life support in China. Bo Sun was the first investigator in China to conduct a multicenter, randomized controlled trial using surfactant for MAS in newborns, and this trial [7] was the first to be approved by the Chinese State Food and Drug Administration which promotes clinical investigations according to the international standard of care [7]. Subsequently, Bo Sun organized seven multicenter studies on neonatal respiratory diseases, in which either descriptive epidemiology or a case-control design was used to characterize the effectiveness of respiratory support among nationwide or province-wide NICU networks by analyz-

Bo Sun and the Development of

Neonatology in China ing the mortality and morbidity of very preterm, late preterm, and term infants with RDS, MAS, and other respiratory disorders [6]. These studies evaluated the efficacy of surfactant, noninvasive and invasive ventilation, and iNO in specific diseases and patient populations, showing that the quality and effectiveness of the current NICUs included in the networks has improved considerably [8]. Bo Sun initiated a multicenter investigation of neonatal respiratory failure in a complete birth registry data file of $>61,000$ live births from a total population of $>5$ million in 2010, in collaboration with a group of obstetricians, neonatologists, and pediatricians in a network in Huai' an, Jiangsu Province. Using this registry, his group of investigators reported for the first time that the preterm birth rate was $3.7 \%$ including all live births of infants $<28$ weeks' gestation; the incidence of neonatal hypoxemic respiratory failure requiring respiratory care was $0.9 \%$, with RDS accounting for nearly two-thirds of this. This was the first report of neonatal and perinatal mortality in a Chinese regional birth registry [9].

Bo Sun has witnessed these dramatic nationwide changes in perinatal-neonatal care. He has made a major contribution to the impressive development of neonatal intensive care in China. Over the years, he has organized a series of international neonatal symposia with the participation of international faculty members. This series has stimulated Chinese clinicians and facilitated the practice of neonatal care in keeping with international guidelines. In addition, he has been very active in organizing domestic collaborative investigations and clinical educational and research programs, which have helped to improve the standard of care nationwide. Beside his efforts in the perinatal-neonatal field, he has conducted several experimental and clinical investigations with support from the National Natural Science Foundation.

Bo Sun has published 87 articles, reviews, and editorials in international journals, more than 80 articles in domestic Chinese journals and more than 10 chapters in textbooks of pediatrics. He serves as an associate editor for 2 journals and is a member of the editorial boards of several prestigious international perinatal, neonatal, and pediatric journals. He has mentored more than 30 young physicians in experimental and clinical science in neonatology, pediatric pulmonology, and pediatric critical care medicine, and he hosts an annual course on developmental physiology and pathophysiology at the University Graduate School for Research Physician Students in Pediatrics. Bo Sun continues to encourage young research students and junior faculty members at his home institute, and is committed to institutional and staff develop-

Neonatology 2017;112:288-290 DOI: $10.1159 / 000478083$ 
ment at several universities and provincial maternity hospitals in the western regions of China.

With his basic research and clinical studies, Bo Sun has provided important insights into pulmonary disease mechanisms. Moreover, his epidemiological research, his well-structured educational programs, the constitution of neonatal networks, and the organization of international scientific workshops and symposia are of great clinical relevance, having had a considerable impact on the quality of neonatal care and thus on neonatal morbidity and mortality in China. Bo Sun has gained an excellent international standing in neonatal and pediatric intensive care, and his many invitations to lectures at major academic meetings outside China reflect his respected status in newborn medicine worldwide. He is one of very few Chinese neonatologists and pediatricians who have received the highest level of recognition and appreciation by the international neonatal and pediatric community.

Despite this, Bo Sun is a very modest person, a hardworking and dedicated scientist, a talented organizer, and has been a warm-hearted friend for 30 years. To relax, Bo Sun loves spending time with his family, reading books on history, and is also fond of classical music, particularly enjoying European operas.

\section{References}

$>1$ Halliday HL, Speer CP: Bengt Robertson: a surfactant pioneer. Biol Neonate 2002;82: 272-273.

-2 Sun B, Kobayashi T, Curstedt T, Grossmann $G$, Robertson B: Application of a new ventilator-multi-plethysmograph system for testing efficacy of surfactant replacement in newborn rabbits. Eur Respir J 1991;4:364-370.

$\checkmark 3$ Rider E, Jobe A, Ikegami M, Sun B: Different ventilation strategies alter surfactant response in preterm rabbits. J Appl Physiol 1992;73: 2089-2096.

4 Sun B, Curstedt T, Robertson B: Surfactant inhibition in experimental meconium aspiration. Acta Paediatr 1993;82:182-189.
5 Sun B, Curstedt T, Robertson B: Exogenous surfactant improves ventilation efficiency and alveolar expansion in rats with meconium aspiration. Am J Respir Crit Care Med 1996; 154:764-770.

-6 Zhu GF, Sun B, Niu SF, Cai YY, Lindwall R, Robertson B: Combined surfactant therapy and inhaled nitric oxide in rabbits with oleic acid induced acute respiratory distress syndrome. Am J Respir Crit Care Med 1998;158: 437-443.

7 Chinese Collaborative Study Group for Neonatal Respiratory Diseases: Treatment of severe meconium aspiration syndrome with porcine surfactant: a multicenter, randomized, controlled trial. Acta Paediatr 2005;94: 896-902.
$>8$ Wang H, Gao X, Liu C, Yan C, Lin X, Yang C, Lin Z, Zhu W, Yang Z, Yu F, Qiu Y, Liu X, Zhou X, Chen C, Sun B; Chinese Collaborative Study Group for Neonatal Respiratory Diseases: Morbidity and mortality of neonatal respiratory failure in China. Surfactant treatment in very immature infants. Pediatrics 2012;129:e731-e740

-9 Sun L, Yue H, Sun B, Han L, Qi M, Tian Z, Lu S, Shan C, Luo J, Fan Y, Li S, Dong M, Zuo X, Zhang Y, Lin W, Xu J, Heng Y; Huai'an Perinatal-Neonatal Study Group: Estimation of birth population-based perinatal-neonatal mortality and preterm rate in China from a regional survey in 2010. J Matern Fetal Neonat Med 2013;26:1641-1648. 